\title{
Diagnostic Accuracy of chest Ultrasonography versus Other Diagnostic Imaging Tools for Identification of Lower Respiratory Diseases in Children
}

\author{
Sherif Mostafa Kamal Reda(1), Hatem Refaat Hablas(1), Mohamed Ali Abboud(2), Moustafa \\ Abdelhafez Zedan(3), Mahmoud Mohamed Abd Elnaby Ghallab(1)
}

\begin{abstract}
1 Department of Pediatrics, 2 Department of Radiology, 3 Department of chest disease, Faculty of Medicine, Al-Azhar University

Corresponding author: Mahmoud Mohamed Abd Elnaby Ghallab, Mobile: 00201002017487, E-Mail: mghallab2010@hotmail.com
\end{abstract}

\begin{abstract}
Background: respiratory distress is the primary diagnosis in nearly $50 \%$ of children admitted to the pediatric emergency room and is a common cause of cardiopulmonary arrest in children. There is substantial variability in the etiology and severity of illness. The presenting clinical findings usually help to determine the type of problem. The causes include pneumonia, bronchial asthma, pneumothorax, acute bronchiolitis and pleural effusion. Objective: the present study was designed to compare chest ultrasound, as a diagnostic tool in the diagnosis of children with acute conditions of $\mathrm{RD}$ with the diagnosis of other radiological tools (Chest X-ray and CT chest. Methodology: this study included 200 infants and children, attending the Paediatric Department in Sayed Galal and Al- Hussein, AL-Azhar University Hospitals and they were suffering from respiratory distress. Their ages ranged from 12 month to 60 months with mean age 32.52 months \pm 13.91 months. Males were 134/200 (67\%) while, females were 66/200 (33\%) with male to female ratio 2.03:1. Results: as regard distribution of patients according to clinical or radiological diagnosis, the study showed that uncomplicated pneumonia $\mathrm{n} 84$ (42.0\%), pneumonia with effusion $\mathrm{n} 32$ (16.0\%), non pneumonic effusion $\mathrm{n} 8(4.0 \%)$, lung abscess $\mathrm{n} 4(2.0 \%)$, pneumothorax $\mathrm{n} 14(7.0 \%)$, lung collapse $\mathrm{n} 16$ $(8.0 \%)$, mediastinal mass $\mathrm{n} 4(2.0 \%)$ and acute bronchiolitis n38 (19.0\%). Conclusion: from our study, we can conclude the following: in view of our study it can be concluded that, chest US offers an important contribution to the diagnostic procedures of pleuro-pulmonary disorders in children, as pneumonia, pneumothorax, pleural effusion, lung abscess, lung collapse, mediastinal mass and acute bronchiolitis.
\end{abstract}

Keywords- RD, Chest X ray, CT chest

\section{INTRODUCTION}

Traditionally, air has been considered the enemy of ultrasound and the lung has been considered an organ not amenable to ultrasonography examination. Chest diagnostic imaging is essential when dealing with a critically ill patient. At present, direct visualization of the lung parenchyma is performed with a chest X-ray (CXR) and computed tomography ${ }^{(1)}$. While, the computed tomographies scan of the chest is considered the gold standard for the imaging diagnosis of all the chest conditions, it is neither inexpensive nor available within the intensive care unit, necessitating potentially dangerous transport to the radiology department. In addition, it exposes the patient to high doses of ionizing radiation. Ultrasound compares favorably with computed tomography scan in the diagnostic ability for some disease conditions, most prominently pneumothorax, where it has a sensitivity of $92 \%$ compared to computed tomography. In addition it is relatively cheap and is readily available at the bedside making it easier and faster than chest X-ray or CT ${ }^{(2)}$. For many years transthoracic ultrasound was limited exclusively to the examination of pleural effusions. However, over the past few years ultrasonography of the pleural space and lung parenchyma is gaining a wide consensus in different conditions in clinical practice, particularly in emergency conditions ${ }^{(3)}$.The limitations of computed tomography along with the risk of ionizing radiations mandate the search for a safe diagnostic tool for patients with suspected pneumonia, with the advent of portable bedside ultrasound ${ }^{(4)}$. Lung ultrasound may be used to distinguish viral from bacterial pneumonia (5). The relative ease of bedside chest ultrasonography (chest ultrasonography) as an interesting alternative method indifferent respiratory situations, because it offers accurate information that is of diagnostic and therapeutic relevance. This is why it is often used by intensivists who ask radiologists for a second opinion in difficult or complicated case studies. 
Diagnostic Accuracy of chest Ultrasonography versus Other Diagnostic Imaging Tools...

Experienced radiologists can integrate chest ultrasound findings with better radiological techniques, which mean that the contribution of a radiologist is often necessary in patient management ${ }^{(1)}$. Chest ultrasound may also influence medical decision-making in the emergency department. In a small series of patients presenting with acute dyspnoea, the use of chest ultrasound changed the diagnosis in $44 \%$ and altered management in $58 \%{ }^{(5)}$.

\section{Aim of the work}

This study aimed to A-to determine diagnostic accuracy of Chest Ultrasound in identification and monitoring of lower respiratory diseases in comparison with other diagnostic imaging tools at pediatric Pulmonology unit, emergency and pediatric clinic Al-Azhar University. B-Construct a protocol as a tool of ultrasound of chest and x-ray in diagnosis and monitoring of child with acute lower respiratory diseases

\section{Paients and methods}

This study was carried out on two hundred children was admitted to the pediatric ward at Al-Hussein and Bab-Elshereya Hospitals, AL-Azhar University with different lower respiratory diseases during the period from January 2017 to January 2018. Informed consent was obtained from the parents of the child before enrolling them in the study. The study was approved by the Ethics Board of Al-Azhar University.

\section{Type of study:}

Prospective comparative study

\section{Design:}

Prospective comparative study with collection of patients from pediatric pulmonology unit, AlAzhar university hospitals in Cairo

\section{Avenue}

Pulmonology Unit at Alhussin and Bab Elshereya hospitals, Al-Azhar University

\section{- Inclusion criteria:}

- Age :from 1 year up to 5 years (Preschool age)

Pediatric patient with lower respiratory symptoms (such as tachypnea, expectoration, hemoptysis , breathlessness, cough, wheeze, or chest pain, Cyanosis Grunting

\section{- Exclusion criteria:}

1 -Children $<1$ year or $>5$ years.

2-Children with other associated extra pulmonary Co morbid diseases e.g.: liver, cardiac or renal diseases.
3- Children refuse to participate in the study

Methodology:

- The enrolled children subjected to the following:

- A-HISTORY

- 1-Full Detailed medical history especially of pulmonary symptoms including cough, purulent expectoration, dyspnea, hemoptysis and fever $>38.0^{\circ} \mathrm{C}$ and symptoms of other system affection.

- B-CLINICAL EXAMINATION:

- 1- General examination especially for vital signs \& body measurements

- 2- Systemic review including all body systems:

- 3- Local Examination of the chest

- Inspection: for example for signs of respiratory distress, the shape of the chest, symmetry and if there is scars, pigmentation or dilated veins.

- Palpation: of the trachea central or not, if there is local chest tenderness, and tactile vocal fremitus.

Percussion: of different areas of the chest.

Auscultation: for air entry, breath sound and adventitious sound.

\section{C-INVESTIGATION:}

1-Routine investigations these include: CBC, CRP, ESR, and liver \& kidney functions, PT, PTT and INR.

2-Plain chest $X$ - Ray:

All patients underwent PA chest $\mathrm{X}$-ray and lateral

- as regard acute conditions x-ray will be on day $0,3,7$ for all cases

- And for chronic cases x-ray will be on day 0 and will repeated if necessary

All the studied children with RD were categorized on the basis of clinical presentation and CXR. They were classified in accordance to the British Thoracic Society guidelines in children (6) as:

1. Uncomplicated pneumonia.

2. Pneumonia complicated with Para-pneumonic effusion.

3. Non pneumonic pleural effusion (Hepatic, or Renal or Nutritional).

4. Lung Collapse.

5. Mediastinal mass or lymphadenopathy.

6. Acute Bronchiolitis.

7. Lung abscess.

8-Pneumothorax

-Chest ultrasound:

All patients underwent chest ultrasound. 
- As regard acute conditions chest ultrasound were done on every other day till day 7 for all cases

- And for chronic cases chest ultrasound were done on day 0 and will repeated if necessary

- Sonography was assessed for the location, shape, size and echogenicity of consolidation as well as necrotic areas, positive air bronchogram, fluid bronchogram and pleural effusion if present.

Chest U/S immediately was done after plain X-ray to all patients. Chest U/S was performed using a SonoScape (at the Ultrasound unit of Chest department) by well trained pulmonologist and a pediatrician who was under training. Ultrasonography examinations techniques were performed following the methodology described by Coley ${ }^{(7)}$.The machine used all through the study was a Sono-Scape model: L743 China, at the Ultrasound Unit of Chest Department, Al-Azhar University. A 3-5 $\mathrm{MHz}$ convex transducer was used for deep lung structures and a high-frequency $5-12 \mathrm{MHz}$ linear array probe was used for visualizing the chest wall, pleura, and the lung peripheral parenchyma as it is more effective in visualizing these structures.

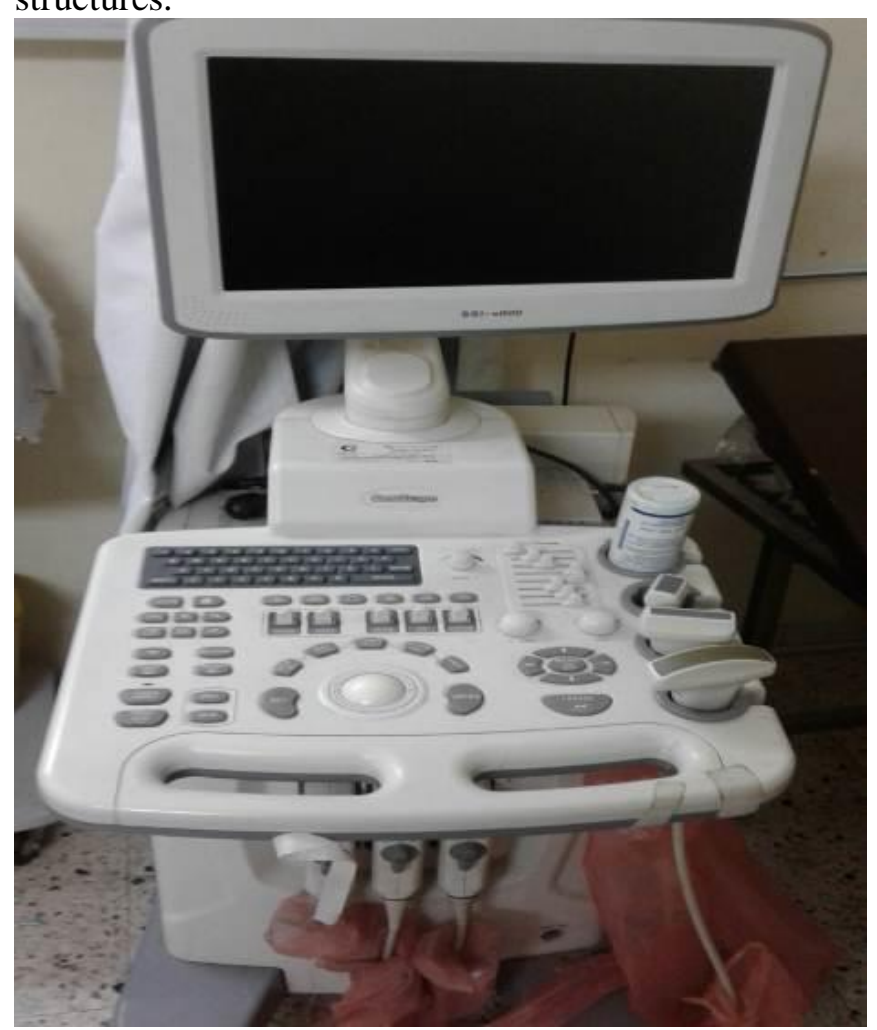

Figure 1: ultrasound machine and probes

\section{Technique:}

1-Probe selection: small infants were easily examined with high frequency (linear transducer) 5-12 MHz, while older children and adolescents require lower frequency transducer (convex transducer) 3-5 $\mathrm{MHz}$.
Linear transducers are valuable for the examination of chest wall lesions ${ }^{(7)}$.

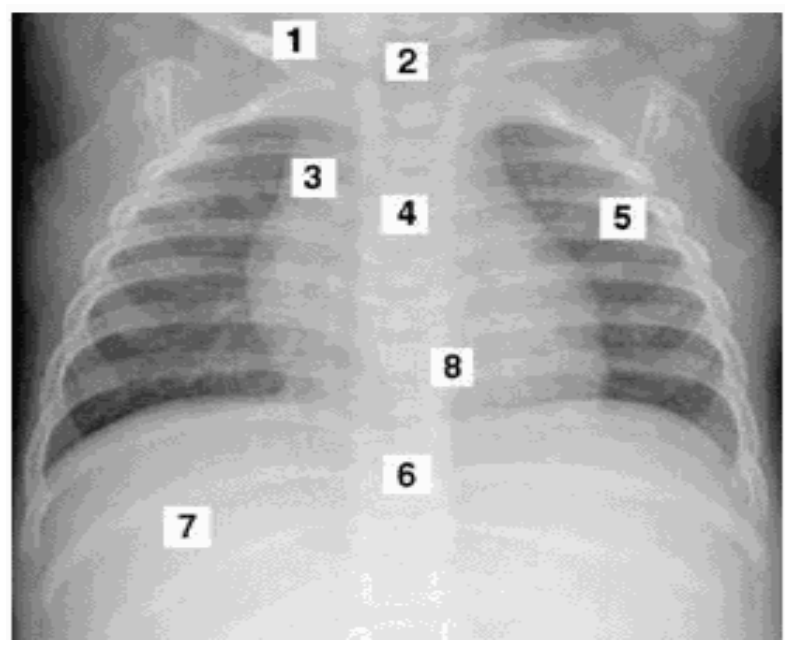

Figure 2: acoustic windows for thoracic sonography: (1) supraclavicular (2) suprasternal, (3) parasternal, (4) transsternal, (5) intercostals, (6) subxyphoid, (7) subdiaphragmatic, and (8) posterior paraspinal ${ }^{(7)}$.

1-Baic B-mode real time US was generally used for chest US. The M-mode imaging was used when needed as in the evaluation of pneumo thorax.

2-Useul acoustic windows were used in the scan. The relatively unossified thorax of the neonate and infant, along with the presence of a relatively large thymus allow imaging of the anterior chest and mediastinum through sternal and costochondral cartilages. Suprasternal or supraclavicular approaches may also be useful in examining the anterior mediastinum and thoracic vessels. Intercostal scanning allowed imaging of the lung and pleura throughout the thorax and the posterior mediastinum. The inferior thoracic cavity can be examined by using the liver, spleen, or fluid filled stomach as acoustic windows.

3-Systemic organized approach was used. This approach divided each hemithorax into 4 quadrants: upper anterior, lower anterior, upper lateral and basal lateral. The anterior axillary line divides the anterior from lateral regions. If the condition of the patient permited, upright posterior imaging should be performed to evaluate the posterior chest and to improve detection of small pleural effusions.

\section{4-CT chest (for selected case)}

Statistical analysis:

Recorded data were analyzed using the statistical package for social sciences, version 20.0 (SPSS Inc., Chicago, Illinois, USA). Quantitative data were expressed as mean \pm standard deviation (SD). 
Diagnostic Accuracy of chest Ultrasonography versus Other Diagnostic Imaging Tools...

Qualitative data were expressed as frequency and percentage.

\section{The following tests were done:}

- A one-way analysis of variance (ANOVA) when comparing between more than two means.

- Chi-square $\left(\mathrm{x}^{2}\right)$ test of significance was used in order to compare proportions between qualitative parameters.

$$
\text { Kappa }=\frac{\text { (Observed Agreement }- \text { Expected Agreement) }}{1 \text { - Expected Agreement }}
$$

- $\quad 0$ - 0.20: Slight agreement

- 0.21-0.40: fair agreement

- 0.41-0.60: Moderate agreement

- 0.61-0.80: Substantial agreement

- 0.81-1: Nearly perfect agreement

- Evaluation of Diagnostic Performance:

- Diagnostic sensitivity:

- It measures the incidence of true positive results in patients groups.

- Diagnostic sensitivity =

$$
\frac{\mathrm{TP}}{\mathrm{TP}+\mathrm{FN}} \times 100
$$

\section{- Where,}

- TP (true positive) is the number of diseased patients accurately classified by the test, and FN (false negative) is the number of diseased patients misclassified by the test.

- The confidence interval was set to $95 \%$ and the margin of error accepted was set to $5 \%$. So, the p-value was considered significant as the following:

- Probability (P-value)

$-\mathrm{P}$-value $\leq 0.05$ was considered significant.

-P-value $\leq 0.001$ was considered as highly significant.

-P-value $>0.05$ was considered insignificant.

\section{RESULTS}

This prospective comparative study included 200 infants and children (134 males and 66 females). Their ages ranged from one12 month to 60 months, attending the Pediatric Department in Sayed Galal and Al- Hussein, AL-Azhar University Hospitals and suffering from respiratory distress.

Table 1: diagnosis of patients presenting with respiratory distress of the studied group $(n=200)$

\begin{tabular}{|l|l|}
\hline Diagnosis Finding & Total $(\mathbf{n}=200)$ \\
\hline Uncomplicated Pneumonia & $84(42.0 \%)$ \\
\hline Pneumonia with effusion & $32(16.0 \%)$ \\
\hline Non Pneumonic effusion & $8(4.0 \%)$ \\
\hline Lung Abscess & $4(2.0 \%)$ \\
\hline Pneumothorax & $14(7.0 \%)$ \\
\hline Lung Collapse & $16(8.0 \%)$ \\
\hline Mediastinal Mass & $4(2.0 \%)$ \\
\hline Acute Bronchiolitis & $38(19.0 \%)$ \\
\hline
\end{tabular}

This table showed distribution among study population according to diagnosis

This table showed that the uncomplicated pneumonia was $84(42.0 \%)$, pneumonia with effusion was $32(16.0 \%)$, non-pneumonic effusion was 8 (4.0\%), lung abscess was 4 (2.0\%), pneumothorax was 14 (7.0\%), lung collapse was 16 $(8.0 \%)$, mediastinal mass was $4(2.0 \%)$ and acute bronchiolitis was 38 (19.0\%).

Table 2: demographic data distribution of the studied group $(\mathrm{n}=200)$

\begin{tabular}{|l|l|}
\hline Demographic data & Total $(\mathbf{n}=\mathbf{2 0 0})$ \\
\hline Gender & \\
\hline Female & $66(33.0 \%)$ \\
\hline Male & $134(67.0 \%)$ \\
\hline Age (Months) & $12-60[32.52 \pm 13.91]$ \\
\hline Residence & \\
\hline Rural & $67(33.5 \%)$ \\
\hline Urban & $133(66.5 \%)$ \\
\hline Parental Smoking & \\
\hline No & $74(37.0 \%)$ \\
\hline Yes & $126(63.0 \%)$ \\
\hline
\end{tabular}

This table showed that the gender female 66 (33.0\%), Male 134 (67.0\%), age (Months) 12-60 $[32.52 \pm 13.91]$, residence $67(33.5 \%)$, urban $133(66.5 \%)$, parental smoking no $74(37.0 \%)$ and Yes $126(63.0 \%)$.

\begin{tabular}{|c|c|c|c|c|c|c|}
\hline \multirow{3}{*}{ Diagnosis Finding } & \multicolumn{4}{|c|}{ Gender } & \multirow{2}{*}{\multicolumn{2}{|c|}{ Chi-square test }} \\
\hline & \multicolumn{2}{|c|}{ Female } & \multicolumn{2}{|c|}{ Male } & & \\
\hline & No. & $\%$ & No. & $\%$ & $\mathbf{x 2}$ & p-value \\
\hline Uncomplicated Pneumonia & 27 & $32.1 \%$ & 57 & $67.9 \%$ & 21.305 & $<0.001 * *$ \\
\hline Pneumonia with effusion & 11 & $34.4 \%$ & 21 & $65.6 \%$ & 5.045 & $0.025 *$ \\
\hline Non Pneumonic effusion & 3 & $37.5 \%$ & 5 & $62.5 \%$ & 3.063 & 0.080 \\
\hline Lung Abscess & 1 & $25.0 \%$ & 3 & $75.0 \%$ & 0.500 & 0.479 \\
\hline Pneumothorax & 6 & $42.9 \%$ & 8 & $57.1 \%$ & 0.139 & 0.709 \\
\hline Lung Collapse & 4 & $25.0 \%$ & 12 & $75.0 \%$ & 6.125 & $0.013 *$ \\
\hline Mediastinal Mass & 2 & $50.0 \%$ & 2 & $50.0 \%$ & 0.000 & 1.000 \\
\hline Acute Bronchiolitis & 12 & $31.6 \%$ & 26 & $68.4 \%$ & 8.873 & $0.003 *$ \\
\hline Total & 66 & $33.0 \%$ & 134 & $67.0 \%$ & 44.890 & $<0.001 * *$ \\
\hline
\end{tabular}

Table 3: relation between gender and diagnosis finding among patients $(n=200)$

p-value $>0.05 \mathrm{NS}$; *p-value $<0.05 \mathrm{~S}$; **p-value $<0.001 \mathrm{HS}$ 
This table showed statistically significant relation between gender with uncomplicated pneumonia, pneumonia with effusion, lung collapse and acute bronchiolitis.

Table 4: relation between age and diagnosis finding among patients $(n=200)$

\begin{tabular}{|l|c|c|}
\hline \multirow{2}{*}{ Diagnosis Finding } & \multicolumn{2}{|c|}{ Age (Months) } \\
\cline { 2 - 3 } & Mean & $\mathbf{\pm S D}$ \\
\hline Uncomplicated Pneumonia & 35.89 & 14.36 \\
\hline Pneumonia with effusion & 35.03 & 10.09 \\
\hline Non Pneumonic effusion & 27.63 & 3.42 \\
\hline Lung Abscess & 57.00 & 2.16 \\
\hline Pneumothorax & 37.00 & 11.00 \\
\hline Lung Collapse & 37.00 & 10.66 \\
\hline Mediastinal Mass & 35.75 & 3.30 \\
\hline Acute Bronchiolitis & 17.53 & 7.20 \\
\hline Total & 32.52 & 13.91 \\
\hline ANOVA & \multicolumn{2}{|c|}{$\mathbf{1 3 . 8 6 1}$} \\
\hline p-value & $\mathbf{0 . 0 0 1}$ ** \\
\hline
\end{tabular}

$* *$ p-value $<0.001 \mathrm{HS}$

This table showed statistically significant relation between age with diagnosis finding.

Table 5: relation between residence and diagnosis finding among patients $(\mathrm{n}=200)$

\begin{tabular}{|c|c|c|c|c|c|c|}
\hline \multirow{3}{*}{ Diagnosis Finding } & \multicolumn{4}{|c|}{ Residence } & \multirow{2}{*}{\multicolumn{2}{|c|}{ Chi-square test }} \\
\hline & \multicolumn{2}{|c|}{ Rural } & \multicolumn{2}{|c|}{ Urban } & & \\
\hline & No. & $\%$ & No. & $\%$ & $\mathbf{x 2}$ & p-value \\
\hline Uncomplicated Pneumonia & 35 & $41.7 \%$ & 49 & $58.3 \%$ & 3.989 & $0.046^{*}$ \\
\hline Pneumonia with effusion & 11 & $34.4 \%$ & 21 & $65.6 \%$ & 5.045 & $0.025^{*}$ \\
\hline Non Pneumonic effusion & 0 & $0.0 \%$ & 8 & $100.0 \%$ & 12.250 & $0.004 *$ \\
\hline Lung Abscess & 0 & $0.0 \%$ & 4 & $100.0 \%$ & 4.500 & $0.034 *$ \\
\hline Pneumothorax & 7 & $50.0 \%$ & 7 & $50.0 \%$ & 0.000 & 1.000 \\
\hline Lung Collapse & 3 & $18.8 \%$ & 13 & $81.3 \%$ & 10.125 & $0.002 *$ \\
\hline Mediastinal Mass & 0 & $0.0 \%$ & 4 & $100.0 \%$ & 4.500 & $0.034 *$ \\
\hline Acute Bronchiolitis & 11 & $28.9 \%$ & 27 & $71.1 \%$ & 11.899 & $0.006^{*}$ \\
\hline Total & 67 & 33.5 & 133 & $66.5 \%$ & 13.690 & $0.002 *$ \\
\hline
\end{tabular}

p-value $>0.05 \mathrm{NS} ; *$ p-value $<0.05 \mathrm{~S}$

This table showed statistically significant relation between residences with diagnosis finding.

Table 6: relation between parental smoking and diagnosis finding among patients $(n=200)$

\begin{tabular}{|l|c|c|c|c|c|c|}
\hline \multirow{2}{*}{ Diagnosis Finding } & \multicolumn{4}{|c|}{ Parental Smoking } & \multicolumn{2}{c|}{ Chi-square test } \\
\cline { 2 - 7 } & \multicolumn{3}{|c|}{ No } & \multicolumn{2}{|c|}{ Yes } & \multicolumn{2}{c|}{ No. } & p-value \\
\cline { 2 - 7 } & No. & \% & No. & \% & x2 & $<0.001^{* *}$ \\
\hline Uncomplicated Pneumonia & 24 & $28.6 \%$ & 60 & $71.4 \%$ & 29.087 & $0.025^{*}$ \\
\hline Pneumonia with effusion & 12 & $37.5 \%$ & 20 & $62.5 \%$ & 5.045 & $0.004^{*}$ \\
\hline Non Pneumonic effusion & 0 & $0.0 \%$ & 8 & $100.0 \%$ & 12.250 & 1.000 \\
\hline Lung Abscess & 2 & $50.0 \%$ & 2 & $50.0 \%$ & 0.000 & $<0.001^{* *}$ \\
\hline Pneumothorax & 14 & $100.0 \%$ & 0 & $0.0 \%$ & 24.143 & 0.289 \\
\hline Lung Collapse & 6 & $37.5 \%$ & 10 & $62.5 \%$ & 1.125 & $0.034^{*}$ \\
\hline Mediastinal Mass & 0 & $0.0 \%$ & 4 & $100.0 \%$ & 4.500 & $<0.001^{* *}$ \\
\hline Acute Bronchiolitis & 7 & $18.4 \%$ & 31 & $81.6 \%$ & 27.881 & $<0.001^{* *}$ \\
\hline Total & 74 & $37.0 \%$ & 126 & $63.0 \%$ & 26.010 & \\
\hline
\end{tabular}

p-value $>0.05 \mathrm{NS}$; *p-value <0.05 S; **p-value <0.001 HS

This table showed statistically significant relation between parental smoking and diagnosis finding. 
Diagnostic Accuracy of chest Ultrasonography versus Other Diagnostic Imaging Tools...

Table 7: diagnosis and radiological finding distribution of the studied group $(\mathrm{n}=200)$

\begin{tabular}{|l|c|}
\hline Diagnosis and radiological Finding & Total $(\mathbf{n = 2 0 0})$ \\
\hline Chest x-ray at admission & $54(27.0 \%)$ \\
\hline Negative & $146(73.0 \%)$ \\
\hline Positive & $11(5.5 \%)$ \\
\hline Chest ultrasound at admission & $189(94.5 \%)$ \\
\hline Negative & \\
\hline Positive & $35(19.2 \%)$ \\
\hline Chest x-Ray follow-up (n=182) & $147(80.8 \%)$ \\
\hline Negative & \\
\hline Positive & $5(2.7 \%)$ \\
\hline Chest UltrasoundFollow-up (n=182) & $177(97.3 \%)$ \\
\hline Negative & $0(0.0 \%)$ \\
\hline Positive & $32(100.0 \%)$ \\
\hline C-T Chest (n=32) & \\
\hline Negative & \\
\hline Positive & \\
\hline
\end{tabular}

This table showed that the chest $x$-ray at admission $146(73.0 \%)$, chest ultrasound at admission 189 (94.5\%), chest X-ray follow-up (n=182) 147 (80.8\%), chest ultrasound follow-up (n=182) 177 (97.3\%) and $\mathbf{C}$-T chest $(\mathbf{n}=\mathbf{3 2}) 32(100.0 \%)$ of diagnosis and radiological finding.

Table (8): Relation between chest $\mathrm{x}$-ray at admission and diagnosis finding among patients $(\mathrm{n}=200)$.

\begin{tabular}{|c|c|c|c|c|c|c|}
\hline \multirow{3}{*}{ Diagnosis Finding } & \multicolumn{4}{|c|}{ Chest X-ray at admission } & \multirow{2}{*}{\multicolumn{2}{|c|}{ Chi-square test }} \\
\hline & \multicolumn{2}{|c|}{ Positive } & \multicolumn{2}{|c|}{ Negative } & & \\
\hline & No. & $\%$ & No. & $\%$ & $\mathbf{x} 2$ & p-value \\
\hline Uncomplicated Pneumonia & 70 & $83.3 \%$ & 14 & $16.7 \%$ & 71.877 & $<0.001 * *$ \\
\hline Pneumonia with effusion & 23 & $71.9 \%$ & 9 & $28.1 \%$ & 10.589 & $0.001 *$ \\
\hline Non Pneumonic effusion & 6 & $75.0 \%$ & 2 & $25.0 \%$ & 2.250 & 0.134 \\
\hline Lung Abscess & 3 & $75.0 \%$ & 1 & $25.0 \%$ & 0.500 & 0.479 \\
\hline Pneumothorax & 10 & $71.4 \%$ & 4 & $28.6 \%$ & 3.560 & 0.059 \\
\hline Lung Collapse & 14 & $87.5 \%$ & 2 & $12.5 \%$ & 15.125 & $<0.001 * *$ \\
\hline Mediastinal Mass & 2 & $50.0 \%$ & 2 & $50.0 \%$ & 0.500 & 0.479 \\
\hline Acute Bronchiolitis & 18 & $47.4 \%$ & 20 & $52.6 \%$ & 0.050 & 0.829 \\
\hline Total & 146 & $73.0 \%$ & 54 & $27.0 \%$ & 82.810 & $<0.001 * *$ \\
\hline
\end{tabular}

p-value $>0.05 \mathrm{NS}$; *p-value $<0.05 \mathrm{~S}$; **p-value $<0.001 \mathrm{HS}$

This table showed statistically significant relation between chest $\mathrm{x}$-ray at admission and uncomplicated Pneumonia, Pneumonia with effusion and lung collapse.

Table 9: relation between chest ultrasound at admission and diagnosis finding among patients $(n=200)$

\begin{tabular}{|c|c|c|c|c|c|c|}
\hline \multirow{3}{*}{ Diagnosis Finding } & \multicolumn{4}{|c|}{ Chest ultrasound at admission } & \multirow{2}{*}{\multicolumn{2}{|c|}{ Chi-square test }} \\
\hline & \multicolumn{2}{|c|}{ Positive } & \multicolumn{2}{|c|}{ Negative } & & \\
\hline & No. & $\%$ & No. & $\%$ & $\mathbf{x 2}$ & p-value \\
\hline Uncomplicated Pneumonia & 80 & $95.2 \%$ & 4 & $4.8 \%$ & 133.700 & $<0.001^{*}$ \\
\hline Pneumonia with effusion & 32 & $100.0 \%$ & 0 & $0.0 \%$ & 164.000 & $<0.001 * *$ \\
\hline Non Pneumonic effusion & 8 & $100.0 \%$ & 0 & $0.0 \%$ & 12.250 & $0.005^{*}$ \\
\hline Lung Abscess & 4 & $100.0 \%$ & 0 & $0.0 \%$ & 4.500 & $0.034^{*}$ \\
\hline Pneumothorax & 14 & $100.0 \%$ & 0 & $0.0 \%$ & 24.143 & $<0.001 *$ \\
\hline Lung Collapse & 16 & $100.0 \%$ & 0 & $0.0 \%$ & 28.125 & $<0.001^{*}$ \\
\hline Mediastinal Mass & 3 & $75.0 \%$ & 1 & $25.0 \%$ & 0.500 & 0.479 \\
\hline Acute Bronchiolitis & 32 & $84.2 \%$ & 6 & $15.8 \%$ & 32.872 & $<0.001^{* *}$ \\
\hline Total & 189 & $94.5 \%$ & 11 & $5.5 \%$ & 56.692 & $<0.001 * *$ \\
\hline
\end{tabular}

p-value $>0.05 \mathrm{NS} ; *$ p-value $<0.05 \mathrm{~S}$; **p-value $<0.001 \mathrm{HS}$ 
This table showed statistically significant relation between chest ultrasound at admission and diagnosis finding.

\section{DISCUSSION}

For many years chest ultrasound was limited exclusively to the examination of pleural effusions. However, over the past few years ultrasonography of the pleural space and lung parenchyma is gaining a wide consensus in different conditions in clinical practice, particularly in emergency conditions. Given its ease of use and bed-side practicality, pleuralparenchymal lung ultrasound can and must offer a useful tool for respiratory specialists ${ }^{(8)}$. Ultrasound (US) has been proposed as an alternative first-line imaging modality to diagnose community-acquired pneumonia in children. Lung US has the potential benefits over chest radiography of being radiation free, subject to fewer regulatory requirements, relatively lower cost and with immediate bedside availability of results ${ }^{(9)}$. Certain anatomical characteristics in children, such as a thinner chest wall and smaller thoracic width and lung mass, facilitate US imaging and ensure good-quality images of the lung. In non-cooperative young patients, the examination is more time consuming but is usually feasible. The examination can be done at the patient's bedside and repeated without radiation risk. Performance of a chest US scan requires less skill than other sonographic scans (of the abdomen or heart, for example) and the learning curve is faster ${ }^{(\mathbf{1 0})}$.Despite that Computed tomography (CT) considered the gold standard in the diagnosis of many pleuro-pulmonary disorders, it is not readily available in centers located far from hospitals; moreover, the transfer and stay of critical patients in the CT service cause several clinical and management problems, above all for emergency departments and resuscitation units, as well as high risks for patients. Furthermore, radiation exposure problems cannot be neglected ${ }^{\left({ }^{11}\right)}$.This is especially important in infants ${ }^{(\mathbf{1 2})}$, who carry a higher risk of cancer from exposure to radiation than people of other ages. Therefore, alternative diagnostic methods that do not involve the use of ionizing radiation should be considered when evaluating young individuals, in order to minimize cancer risk ${ }^{(13)}$. The present study was designed to compare chest ultrasound, as a diagnostic tool in the diagnosis of children with acute conditions of RD with the diagnosis of other radiological tools (chest $\mathrm{X}$ ray and CT chest). This study included 200 infants and children, attending the Paediatric Department in Sayed Galal and Al- Hussein, AL-Azhar University Hospitals and they were suffering from respiratory distress. Their ages ranged from 12 month to 60 months with mean age 32.52 months \pm 13.91 months. Males were $(134 / 200) 67 \%$ while females were (66/200) $33 \%$ with male to female ratio 2.03:1. From the studied samples of children $66.5 \%$ were urban inhabitants while, $33.5 \%$ were rural inhabitants. This comes in agreement with the study done in Kenya and Gambia; that reported that urban children had a higher rate of hospitalization for respiratory episodes than rural children; which is thought to be related to the distance of hospital facility ${ }^{(14)}$. In contrast to results of Awadalla et al. ${ }^{\left({ }^{(15)}\right.}$ they reported that nearly three quarters $74.2 \%$ of recorded cases with Acute Respiratory Illnesses (ARIs) came from rural inhabitants this could be explained by the fact that; in rural areas of developing countries, there is burning biomass principally wood and crop residues which are an important source of exposure to a variety of toxins.Our study showed that $63 \%$ of the studied children with RD had been exposed to passive smoking, this comes in agreement with results of Azad et al. ${ }^{(16)}$ who reported that among the children with ARIs $50.5 \%$ were exposed to passive smoking. Friguls et al. ${ }^{(17)}$ discussed that tobacco smoking during pregnancy increases the prevalence of hospitalization of infants after birth due to lower respiratory infections particularly during the first two years of life. All the studied children $(n=200)$ who were diagnosed with respiratory distress on basis of clinical examination, underwent chest ultrasonography and chest X rays and CT chest for selected cases on need. As regard distribution of patients according to clinical or radiological diagnosis, the study showed that uncomplicated pneumonia n84 (42.0\%), Pneumonia with effusion n32 (16.0\%), Non Pneumonic effusion n8 $(4.0 \%)$, lung abscess n4 (2.0\%), Pneumothorax n14 (7.0\%), Lung Collapse n16 (8.0\%), mediastinal mass $\mathrm{n} 4$ (2.0\%) and acute bronchiolitis n38 (19.0\%).In agreement with results of Elsaeed et al. ${ }^{(18)}$ who reported that out of 50 patients included in their study, the majority $(46 \%)$ were diagnosed as uncomplicated pneumonia, $16 \%$ had parapneumonic effusion, $6 \%$ had non pneumonic effusion, $6 \%$ had lung collapse, $4 \%$ had lung abscess and $4 \%$ had pneumothorax.

In our study, among patients in whom uncomplicated pneumonia was diagnosed $(n=84) ; 70$ of them were diagnosed by using chest $\mathrm{X}$ - ray where pneumonia was diagnosed in 80 patients on chest ultrasound. So, LUS showed findings consistent with pneumonia in (80/84) children with sensitivity $95.2 \%$, while CXR was positive for pneumonia in (70/84) children with sensitivity $83.3 \%$. In the our study, pneumothorax was diagnosed by chest US for the following findings (absent lung sliding, absent B-lines, absent lung pulse, barcode sign and lung point sign. Among patients in whom lung collapse was diagnosed $(n=16)$; only 14 
Diagnostic Accuracy of chest Ultrasonography versus Other Diagnostic Imaging Tools...

patients $(87.5 \%)$ were diagnosed by chest $\mathrm{X}$ - rays and lung collapse were identified in all the 16 patients (100\%)on chest ultrasonography and all cases were diagnosed by CT chest (100\%). Similarly, Lichtenstein et al. ${ }^{(19)}$ demonstrated that; in the atelectasis group, air bronchograms yielded a dynamic air bronchogram in 1 out of $16(6.25 \%)$ patients, while static air bronchogram was detected in 15 out of $16(93.75 \%)$ patients. In the our study, there were 4 cases with mediastinal masses, the 4 cases were lymphomas, chest $\mathrm{X}$ - ray identify 2 cases $(50 \%)$ chest US was able to visualize the three cases $(75 \%)$ with mediastinal masses while CT chest identify all( $100 \%)$. In agreement with the study of Kim et al. ${ }^{(20)}$ we found in this study that US imaging offers several advantages over traditional radiographic techniques: it is noninvasive and painless. Furthermore, US may have a role in the evaluation of mediastinal masses.

There are some limitations to this study; the sample size was small and therefore, confirmatory data on larger sample size are needed. On the other hand, because the value of chest US for detecting pleuropulmonary disorders has been demonstrated in adults, it seems obvious that similar results may be confirmed in the paediatric age. US scans should be performed by a single expert operator, and it is reasonable to hypothesise that similar results cannot be immediately achieved by less experienced operators. However, it should be considered that learning the technique and image interpretation is relatively simple and fast process. Unfortunately, not all radiologists are minded with pediatric chest ultrasonography, and their knowledge is limited only to pleural findings, especially pleural effusions, so this issue added an extra-limitation in examining our cases as the experienced operator was not always available. Another limitation is that abnormalities not revealed by chest X-ray were not confirmed by CT scans which cannot be routinely performed and also the stay of critical patients in the CT service causes several clinical and management problems, so we considered chest X- ray as our gold standard test only.

\section{CONCLUSION}

From our study, we can conclude the following: in view of our study it can be concluded that, chest US offers an important contribution to the diagnostic procedures of pleuro-pulmonary disorders in children, as pneumonia, pneumothorax, pleural effusion, lung abscess, lung collapse, mediastinal mass and acute bronchiolitis.

\section{RECOMMENDATION}

1. The use of chest ultrasound can be adopted as a simple and non-invasive method for evaluating children with pleuro pulmonary disorders. It is easy to perform at the patient's bedside, allows close follow-up and avoids the use of ionizing radiation.

2. The studies should be conducted both in resource limited as well as resourceful settings as different questions could be answered such as effectiveness as a diagnostic tool and its role in the follow up.

3. Training of pediatricians on the use of chest US especially in ER which can help rapid diagnosis with minimal handling of patients and less risk of radiation exposure.

4. Further studies are needed for role of chest US in PICU to guide intensivist for proper decision making

\section{REFERENCES}

1. Prithviraj D and Suresh A (2014): Chest ultrasonography: A quick and accurate diagnostic tool in pediatric emergency department and intensive care unit. International Journal of Scientific Study, 2(2): 58-69.

2. Bouhemad B, Zhang M, Lu Q et al. (2007): Clinical review: Bedside lung ultrasound in critical care practice. Crit. Care, 11(1): 205-210.

3. Stefan R, Shalim JR, Charlotte G et al. (2017): Lung ultrasound as a diagnostic tool for radiographically-confirmed pneumonia in low resource settings. Respiratory Medicine, 128: 57-64.

4. Vito Antonio C, Luna G, Silvana C et al. (2011):Lung ultrasound in bronchiolitis: Comparison with chest X-ray. European Journal of Pediatrics, 7(3): 70-81.

5. Shah VP, Tunik MG and Tsung JW (2012): Prospective Evaluation of Point-ofCare Ultrasonography for the Diagnosis of Pneumonia in Children and Young Adults. Arch. Pediatr. Adolesc. Med., 10: 1-7.

\section{British Thoracic Society (2011):} Guidelines for Community Acquired Pneumonia in children, Oct, 2011, available at: https:// www. brit-thoracic. org. uk/document -library/ clinical- information/ pneumonia/ paediatric-pneumonia/ btsguidelines- for- the- management- ofcommunityacquired- pneumonia- inchildren 
7. Coley B (2011): Chest Sonography in children: Current indications, techniques, and imaging findings. Radiologic Clinic of North America, 49 (5): 825 - 846.

8. Smargiassi A, Inchingolo $\mathrm{R}$, Soldati $\mathrm{G}$ et al. (2013): The role of chest ultrasonography in the management of respiratory diseases: document II. Multi. Discip. Respir. Med., 8(1):55-63.

9. Jacob AM, Savvas A and Heather J (2017): Lung ultrasound for the diagnosis of community-acquired pneumonia in children. Zar. Pediatr. Radiol., 47(11): 1412-1419.

10. Bedetti G, Gargani L, Corbisiero A et al. (2006): Evaluation of ultrasound lung comets by hand-held echocardiography. Cardiovasc. Ultrasound, 3: 4-34.

11. Garofalo GM, Busso F, Perotto A et al. (2006): Fava ultrasound diagnosis of pneumothorax. Radiol. Med., 111: 516-520.

12. Picano E, Frassi F, Agricola $\mathrm{E}$ et al. (2006): Ultrasound lung comets: $A$ clinically useful sign of extravascular lung water. J. Am. Soc. Echocardiogr., 19: 356363.

13. Brenner DJ, Hall EJ and Phil D (2007): Computed tomography an increasing source of radiation exposure. N. Engl. J. Med., 357: 2277-2284.
14. Bigogo G, Audi A, Aura B et al. (2010): Health seeking patterns among participants of population-based morbidity surveillance in rural western Kenya: implications for calculating disease rates. Int. J. Infect. Dis., 14: 967-973.

15. Awadalla HI, El-kholy NF and Barkat AB (2008): Trends of influenza infection in Egypt during two consecutive seasons. Journal of Public Health, 17(3): 195-203.

16. Azad MY, Bahauddin MD, Uddin $\mathrm{H}$ et al. (2014): Indoor air pollution and prevalence of acute respiratory infection among children in rural area of Bangladesh. J. Biol. Agr. Health, 4: 2-12.

17. Friguls B, Garcia-Algar O, Puig $\mathrm{C}$ et al. (2009): Perinatal exposure to tobacco and respiratory and allergy symptoms in first years of life. Arch. Bronconeumol., 45(12):585-590.

18. Elsaeed YA, Shaheen MA, Madkour AM et al. (2013): critical appraisal of ultrasonography as a diagnostic tool in diagnosis of pleuro-pulmonary disorders in children: Thesis submitted for partial fulfillment of MD in Pediatrics Ain Shams University.Cairo.

19. Lichtenstein $D$, Mezière $G$ and Seitz $J$ (2009): The dynamic air bronchogram. An ultrasound sign of alveolar consolidation ruling out atelectasis. Chest, 135: 1421-5.

20. Kim KI, Muller NL and Mayo JR (2000): Clinically suspected pulmonary embolism: utility of CT. Radiology, 210:693-700. 